\title{
LETTER
}

\section{Bcl-xL affects the development of functional CD4 Tregs}

\author{
Amir Sharabi*1,2 and Edna Mozes ${ }^{1}$ \\ See related research by Haque et al., http://arthritis-research.com/content/12/2/R66
}

We read with great interest the article by Haque and colleagues [1] in a recent issue of Arthritis Research \& Therapy. They hypothesized that co-transduction of $\mathrm{CD} 4^{+}$ $\mathrm{T}$ cells with both forkhead box P3 transcription factor (FoxP3) and $\mathrm{Bcl}-\mathrm{xL}$ will generate highly reactive regulatory $\mathrm{T}$ cells (Tregs) that can be used to prevent autoimmune disease. The authors showed that the accumulation, persistence, and efficient function of Tregs were attributable to the expression of Bcl-xL in CD4 Tregs.

Indications for a potential role of $\mathrm{Bcl}-\mathrm{xL}$ in the development of functional Tregs were first described by our group, and the results of studies supporting this notion were published in numerous journals (for example, [2-5]). Because this information was not mentioned in the article by Haque and colleagues [1] and because the results presented in their article confirm our previous studies [2-5], we think that it is important, scientifically and ethically, to acknowledge these data.

Our group has been studying systemic lupus erythematosus (SLE) and developed a tolerogenic peptide, namely hCDR1, shown to ameliorate manifestations of the disease through several mechanisms of action, including the induction of CD4 Tregs [2]. We showed that Bcl-xL was upregulated in CD4 Tregs of SLE-affected (NZBxNZW)F1 mice following treatment with the tolerogenic peptide [3]. Bcl-xL played a suppressive role in the tolerized mice, as it inhibited the activation of $\mathrm{T}$ and $\mathrm{B}$ cells, and mediated the downregulating effects of hCDR1 on the production of the pathogenic cytokines interferon-gamma and interleukin-10 and the upregulating effects on the immunosuppressive cytokine transforming growth factor-beta (TGF- $\beta$ ). Furthermore, CD4 Tregs of the tolerized mice elicited the expression of Bcl$\mathrm{xL}$ in the effector CD4 cells, thus contributing to the

\footnotetext{
*Correspondence: amir.sharabi@weizmann.ac.il
}

'Department of Immunology, The Weizmann Institute of Science, 240 Hertzl Street, Rehovot 76100, Israel

Full list of author information is available at the end of the article amelioration of SLE manifestations [3]. Although CD8 Tregs could not trigger the expression of Bcl-xL in effector CD4 cells, the former cells were essential for the optimal inhibitory function of CD4 Tregs [4]. Finally, we demonstrated that $\mathrm{Bcl}-\mathrm{xL}$ played a role in inducing the regulatory/inhibitory molecules FoxP3, cytotoxic $\mathrm{T}$ lymphocyte antigen 4 (CTLA-4), and TGF- $\beta$ and in repressing PD-1 (programmed death 1) [5]. We showed that Bcl-xL also mediated the induction of CTLA-4 and TGF- $\beta$ in effector CD4 cells by CD4 Tregs of the tolerized mice, thus explaining the inhibition of proliferation and the decreased activation of effector CD4 cells [5]. These newly described roles of $\mathrm{Bcl}-\mathrm{xL}$ may provide a novel mechanism of induction of CD4 Tregs. All together, our data [2-5], supported by those presented by Haque and colleagues [1], suggest that immunomodulation of Bcl-xL expression in $\mathrm{T}$ cells might be valuable for controlling and treating diseases that are affected by CD4 Tregs.

\section{Abbreviations}

CTLA-4, cytotoxic T lymphocyte antigen 4; FoxP3, forkhead box P3 transcription factor; SLE, systemic lupus erythematosus; TGF- $\beta$, transforming growth factor-beta; Treg, regulatory T cell.

\section{Competing interests}

The authors declare that they have no competing interests.

\section{Author details}

'Department of Immunology, The Weizmann Institute of Science, 240 Hertzl Street, Rehovot 76100, Israel. 2Department of Internal Medicine B, The Tel Aviv Sourasky Medical Center, 6 Weizmann Street, Tel Aviv 64239, Israel.

Published: 23 July 2010

\section{References}

1. Haque R, Lei F, Xiong X, WU Y, Song J: FoxP3 and BCl-xL cooperatively promote regulatory $\mathrm{T}$ cell persistence and prevention of arthritis development. Arthritis Res Ther 2010, 12:R66.

2. Sharabi A, Zinger H, Zborowsky M, Sthoeger ZM, Mozes E: A peptide based on the complementarity-determining region 1 of an autoantibody ameliorates lupus by up-regulating CD4+CD25+ cells and TGF-beta. Proc Natl Acad Sci U S A 2006, 103:8810-8815.

3. Sharabi A, Luger D, Ben-David H, Dayan M, Zinger H, Mozes E: The role of apoptosis in the ameliorating effects of a CDR1-based peptide on lupus manifestations in a mouse model. J Immunol 2007, 179:4979-4987.

4. Sharabi A, Mozes E: The suppression of murine lupus by a tolerogenic peptide involves foxp3-expressing CD8 cells that are required for the optimal induction and function of foxp3-expressing CD4 cells. J Immunol 
2008, 181:3243-3251.

5. Sharabi A, Lapter S, Mozes E: BCl-xL is required for the development of functional regulatory CD4 cells in lupus-afflicted mice following treatment with a tolerogenic peptide. J Autoimmun 2010, 34:87-95. doi:10.1186/ar3076

Cite this article as: Sharabi A, Mozes E: BCl-xL affects the development of functional CD4 Tregs. Arthritis Research \& Therapy 2010, 12:405. 